\title{
Oncology and Palliative Care
}

\author{
C. Bausewein R. Hartenstein
}

4. Medizinische Abteilung (Onkologie, Hämatologie, Pneumologie, Palliativmedizin), Städtisches Krankenhaus München-Harlaching, Akademisches Lehrkrankenhaus der Ludwig-Maximilians-Universität, München

\section{Key Words}

Oncology · Palliative care · Palliative medicine

Symptom control · Death and dying

\begin{abstract}
Summary
Oncology developed as a discipline over the last decades. Treatment is concentrated on cure or palliation of the illness with the help of chemotherapy, radiotherapy or surgery. Palliative care has its origin in the hospice movement that started around 1960 in the UK. Centre of care is the patient and his family. Focus of care has moved from quantity to quality of life. Symptom control, communication, rehabilitation and care for the dying are main areas of palliative care. Palliative care and palliative medicine have only developed over the last 10 years in Germany. It is still seen as care for the dying after completion of oncological treatment. The integration of palliative care in earlier stages of the disease is essential to offer a continuity of care for the patient and his family. Principles of palliative care need also be part of medical and post-graduate training.
\end{abstract}

In G ermany nearly 340,000 patients are diagnosed with cancer every year [1]. $45 \%$ of the patients undergo curative treatment of which about $15 \%$ relapse and will continue with palliative treatment. 55\% are treated in a palliative way from the very beginning [2]. A fter oncological treatment including chemotherapy, radiotherapy and/or surgery, about 210,000 patients in G ermany die of cancer every year [3].

\author{
Schlüsselwörter \\ Onkologie · Palliativbetreuung · Palliativmedizin · \\ Symptomkontrolle $\cdot$ Sterben und Tod
}

\section{Zusammenfassung}

Onkologie ist erst in den letzten J ahrzehnten zu einer eigenständigen Disziplin geworden. Die Behandlung konzentriert sich mit der Hilfe von Chemo-, Strahlentherapie und Chirurgie auf Heilung oder Palliation der Erkrankung. Palliativbetreuung hat ihren Ursprung in der Hospizbewegung, die um 1960 von England ausging. Der Mittelpunkt der Betreuung ist der Patient und seine Familie. Lebensqualität steht im Zentrum der Betreuung, nicht mehr Quantität. Symptomkontrolle, Kommunikation, Rehabilitation und Begleitung in der Sterbephase sind die Schwerpunkte der Palliativbetreuung. Palliativbetreuung und Palliativmedizin haben sich erst in den letzten $10 \mathrm{~J}$ ahren in Deutschland entwickelt. Palliativbetreuung wird immer noch als Sterbebegleitung gesehen, die erst nach der Beendigung onkologischer Behandlung zum Tragen kommt. Die Integration von Palliativbetreuung in frühere Krankheitsstadien ist wesentlich, um eine Kontinuität der Betreuung für Patienten und ihre Angehörigen zu ermöglichen. Die Prinzipien der Palliativbetreuung und Palliativmedizin müssen außerdem Teil der medizinischen Ausbildung und der ärztlichen Weiterbildung werden.

\section{Oncology}

O ncology as a discipline has only developed in the last 50 years. With more and new cytotoxic agents or the combination of them remarkable success in the treatment of cancer patients has been reached. M ajor efforts have gone into trials to show tumour response to new drugs, to find out more about effects

\begin{tabular}{ll}
\hline KARGER & ○ 2000 S. Karger G mbH , Freiburg \\
Fax +49 761 4520714 & A ccessible online at: \\
$\begin{array}{l}\text { E-mail Information@K arger.de } \\
\text { www.karger.com }\end{array}$ & www.karger.com/journals/onk
\end{tabular}

Dr. med. Claudia B ausewein

4. M edizinische A bteilung (O nkologie, Hämatologie, Pneumologie, Palliativmedizin)

Städt. K rankenhaus $M$ ünchen- $H$ arlaching

A kademisches $L$ ehrkrankenhaus der $L$ udwig-M aximilians-U niversität

Sanatoriumsplatz 2, D-81545 M ünchen (G ermany)

Tel. +49 89 62 10-2849, Fax -2851 
and side-effects of these agents and to develop standardised protocols. The fact that about half of the cancer patients are still dying of their illness is not reflected in oncological research projects or publications. With better treatment options in the last decades 'cancer came to be regarded as a disease of organ dysfunction rather than an illness - an illness with psychological and spiritual dimensions embracing both the patient and the patient's family and the community' [4].

\section{Palliative Care}

Palliative care equally seems to be a rather new discipline with its roots in the 1960s in the UK, but looking back to the beginning of the 20th century, palliation was the main task of a doctor because there was hardly any cure. This situation is expressed by the 16th century aphorism 'To cure sometimes, to relieve often, to comfort always' [4]. It was Dame Cicely Saunders, an English nurse and social worker, who decided to become a doctor in order to care for the dying. She trained at St. Joseph's Hospice in London to get to know the hospice philosophy and its principles and to see the patient and the relatives as the centre of care. She also realised the need for better pain and symptom management and started research in pain therapy. D ame Cicely founded St. Christopher's H ospice in London in 1967 with the vision of developing a centre of excellence for the care of the dying and their relatives. From St. Christopher's the world-wide hospice movement took its origin and spread firstly to countries such as A ustralia, N ew Zealand, USA and Canada and then throughout the world. In 1975 B alfour M ount used the expression 'palliative' for the first time when he opened the Palliative Care Service at the R oyal V ictoria Hospital in Montreal, Canada. [5]. The U K is still the motherland of hospice and palliative care. Since 1987 doctors have specialised in palliative medicine in the U K. In 1999 there were 3,342 in-patient beds in 236 hospices and 209 hospital palliative care/support teams [6]. A t the moment in the U K are 6 chairs of palliative medicine, 1 of palliative care and policy and 1 of palliative nursing [6].

The development in Germany is about 25 years behind. The first palliative care unit was opened in 1983 at the U niversity Hospital of Cologne. U ntil 1990 only 2 more palliative care units followed. The last 10 years have however seen a rapid development of palliative care services in G ermany. In 1999 we have about 50 palliative care units linked to hospitals, but only 5 units at university hospitals. There are also 64 hospices which care for the dying who cannot be looked after at home but do not need hospital care [7]. In 1999, the fist chair of palliative medicine was being established at the U niversity of Bonn.

$\mathrm{H}$ ospices are mainly seen as places, which nurse the dying, but palliative care as 'hospice medicine' is more than 'terminal care'. In 1990, the WHO defined palliative care as follows:

'Palliative care is the active total care of patients whose disease is not responsive to curative treatment. Control of pain, of other symptoms, and of psychological, social and spiritual symptoms is paramount. The goal of palliative care is achievement of the best quality of life for patients and their families. $M$ any aspects of palliative care are also applicable earlier in the course of the illness, in conjunction with anticancer treatment. Palliative care:

- affirms life and regards dying as a normal process;

- neither hastens nor postpones death;

- provides relief from pain and other distressing symptoms;

- integrates the psychological and spiritual aspects of patient care;

- offers a support system to help patients live as actively as possible until death;

- offers a support system to help the family cope during the patient's illness and in their own bereavement' [8].

The patient is seen as a whole person with physical, psychological, social and spiritual needs and not just as an illness. The aim is to comfort the patient and his family. Focus of care has moved from quantity to quality of life.

The WHO definition does not limit palliative care to any special disease, e.g. cancer, but is open to all illnesses that are progressive and which limit the prognosis of the patient. Traditionally cancer patients are still the largest group because of the variety of symptoms weeks and months before their death. Patients with motor neurone disease, A IDS or far advanced heart or pulmonary disease are also looked after by palliative care physicians. D octors involved in palliative care come from different specialities, such as general medicine, oncology, radiotherapy, anaesthesiology or neurology. Therefore no discipline can claim palliative care as its own.

Symptom control, communication, rehabilitation and care for the dying can be seen as four main areas of palliative care.

\section{Symptom Control}

B ruera [9] summarises the prevalence of symptoms in patients with advanced cancer as shown in table 1.

Most of the patients suffer different symptoms at the same time. It is one of the main tasks of doctors to provide good symptom management with clear and simple therapies that can be continued at home and therefore do not bind the patient to the hospital.

\section{Communication}

Communication is crucial in every part of medicine. It is not specific to palliative care but it is essential. We need to know what the questions of the patients and their families are, what their needs and anxieties are, how they see their situation and what their expectations are. B reaking bad news is not only an issue at the time of diagnosis of a life-threatening illness but throughout the whole course of the illness. For a patient who is expecting cure it is bad news if oncological treatment fails, for a patient who hopes to live some more years it is bad news if the illness is progressive or if death is imminent. We have to be truthful with our patients even if it is painful and at times hard to admit our powerlessness. Communication means also speaking a language that the patient and the family can understand and admitting that there are questions that do not have answers. 
Table 1 Prevalence of symptoms in 275 consecutive patients with advanced cancer

\begin{tabular}{ll}
\hline Symptom & Prevalence, \% \\
\hline A sthenia & 90 \\
A norexia & 85 \\
Pain & 76 \\
Nausea & 68 \\
Constipation & 65 \\
Sedation - confusion & 60 \\
Dyspnoea & 12 \\
\hline
\end{tabular}

\section{Rehabilitation}

A s the illness progresses, the patients are likely to become more disabled. We can very often see what is not possible any more, but the patients need our support and help to see what they are still able to do. Physiotherapy and occupational therapy assist the patient to gain mobility. Music and art therapy help the patients to express themselves in a non-verbal way or to cope better with their limited situation.

\section{Care for the Dying}

When life is coming to an end, it is the task of all involved in palliative care to comfort the dying person, to ensure good symptom control and to create an atmosphere in which dying with dignity is possible. Patients need us, and we must not walk away from them but accompany them. The families often need special support to cope with the death of their relative at this time. B ereavement support is also a major aspect of palliative care.

\section{Palliative Care Provision}

The idea of palliative care can be realised in different settings. M ost patients want to stay at home as long as possible. To meet their needs, home care nurses or home care teams support general practitioners and district nurses in looking after patients at home. Some of these nurses or teams are attached to in-patient units. Hospital support teams work as advisory services within a hospital setting. They provide advice on symptom control and psychological support for patients, relatives and carers. Hospital support teams bring the principles of palliative care into the acute hospital setting. A distinction has been made within the German system between hospices and palliative care units. Palliative care units are connected to a hospital and specialised in pain and symptom control. They look after patients with special or difficult symptoms or psychosocial problems. Hospices on the other hand care for patients with a life-threatening illness who do not need hospital care but cannot stay at home. The medical care of a patient in a hospice lies in the hand of the general practitioners.

\section{Interface of Oncology and Palliative Care}

In 'C ancer pain relief and palliative care' the WHO stated in 1990 that 'palliative care attracts few of the available cancer control resources. M ost of the resources are devoted to curative treatment, at a relatively high cost but with limited effect' [8]. This has not really changed much since this statement 10 years ago. Similarly the clinical situation shows that most patients are treated by their oncologists until the disease is progressive despite chemotherapy or other disease-modifying strategies. A t that point many patients are still dismissed with the sentence that 'nothing more can be done'. M any oncologists are not aware that there is a lot that can be done, but that we have to change our aims and our points of view. E ven if hope for cure is lost, there is still hope for pain relief and symptom control, quality of life and dying with dignity. A s long as doctors define success only as cure, medicine will fail. But if good pain relief and symptom control, honest communication and a peaceful death are accepted as a valuable outcome, then the needs of our patients as human beings will be met.

I nterestingly palliative care has developed over the last 30 years world-wide as a discipline in its own rite, but only in the last 15 years in Germany. It is only now that oncologists detect palliative care as a necessary and vital part of their discipline. Palliative care is however still seen as an unusual discipline and a luxury for a small group of patients after the completion of oncological treatment. We have to strive for the integration of palliative care into the existing system. A s the possibility of cure decreases, palliative care has to increase. Oncological treatment and palliative care have to go hand in hand and not come one after another. O ncologists have to learn to integrate palliative care into their practice as half of their patients with cancer will still die of their disease. A s well as the integration of palliative care into cancer treatment, a concept has to be developed how patients should be treated if tumour therapy fails. This concept must not be bound to a hospital or another institution or to a palliative care unit but must be transferable to the patients homes. 'Palliative care should follow the patient' as the National Council for Hospice and Specialist Palliative Care Services expresses in a statement [10].

O ne of the main problems is still a lack of knowledge and skills in palliative care. Most aspects of palliative care including a holistic approach, symptom management and communication skills are not yet part of medical training. It is not even integrated in the training of oncologists and radiotherapists. The E uropean Society for M edical O ncology (E SM O) emphasises now the need for palliative care with its new E SM O Task Force on the Integration of Palliative Care into Medical Oncology. The task force strengthens the 'need for continuum in patient care in which both primary therapies and palliative interventions are integrated according to the clinical circumstances of the patient ... all medical oncologists must be expert in the administration of palliative care and that this aspect of care must be fully integrated into cancer services' [11]. This are very high demands for oncologists to become an expert in their field as well as in palliative care. It is a challenge but they can be overtaxed in their responsibilities. More helpful is the differentiation of the $\mathrm{N}$ ational Council for $\mathrm{H}$ ospice and Specialist Palliative Care Services in the U K between the palliative care approach and specialist palliative care services. The palliative care approach 'aims to promote both physical and psychosocial well-being. It is integral part of all clinical practice, whatever the illness or its stage, informed by a knowledge and practice of 
palliative care principles. Specialist palliative care services are those services with palliative care as their core speciality' [10]. Specialist palliative care services provide 'physical, psychological, social and spiritual support, with a mix of skills, delivered through a multiprofessional, collaborative team approach. They require a high level of professional skills from trained staff, a high staff-patient ratio, set standards for education and training and evaluate treatment and outcome with clinical audit and research programmes' [10]. This two areas complement each other in improving quality of care depending on the patient's situation. That means that not every doctor and not every oncologist has to become a specialist in palliative care. Especially palliative care and oncology must not be mixed up because they are not the same. Derek Doyle expressed this in a talk he gave on an international workshop on ' $G$ oals of Palliative Cancer Therapy' when he said that 'palliative care and oncology are sister disciplines but they are not the same thing. Just as specialist palliative medicine physicians cannot, should not, claim to be oncologists, so should oncologists not assume that they are experts in the provision of palliative care nor attempt to own the new speciality' [12].

$M$ acD onald summarises what cancer centres and palliative care units can learn from each other [4]: Cancer centres will recognise the importance of continuity of care, assessment of pain and other symptoms, relief of symptoms with attention to detail, importance of hierarchy of problems which might differ between patient, family and professionals, importance of home care and opportunity of joint clinics. $O \mathrm{n}$ the other hand, palliative care groups have to look more self-critical than 'messianic' on the care they deliver, emphasise on quality research and enhance access to palliative anticancer therapy.

\section{Challenges for the German Situation}

If we want to improve the situation of dying people in Germany, palliative care has to be implemented in our health care system. The need for more palliative care units as models for palliative care is obvious when we compare the number of beds in the U K and in G ermany. 155,000 people die of cancer in the UK in 1 year. For these patients exist 3,200 beds in over 200 hospice and palliative care units in the UK [6]. In contrast, in G ermany die about 210,000 patients of cancer every year. In A pril 1999 existed 114 palliative care units and hospices with about 1,000 beds for these patients [7]. Palliative care units should exist in university hospitals, cancer centres and general hospitals. These palliative care units have to become centres of competence for care, teaching and research. A s specialist units cannot be opened in every hospital, other forms for implementation of palliative care have to be found. Hospital support teams or palliative care consulting services without own beds should be developed in every hospital.

Palliative medicine has to become an integral part of medical curricula and enter medical training both for students and post-graduates. Consequently it must become part of examinations to make sure that it is not only dealt with on a voluntary basis.

Palliative care has to be recognised as an own speciality or at least subspeciality. This is necessary to improve quality of care for patients and relatives, to have specialists to train students and other doctors and to get greater attention within the medical world and the public.

R esearch has to become an integral part of palliative care to validate pain and symptom management, to show improvements in quality of life and other outcome measures, and to prove cost-effectiveness. In consequence more resources, especially financial support, have to be provided for palliative care projects.

Palliative care with its radical patient orientation has to offer a lot to our existing medical system. Communication, co-operation and co-ordination of existing services, especially in oncology and palliative care, can make a difference to improve the quality of life of patients with life-threatening diseases and their relatives.

\section{References}

1 Schön D, B ertz $\mathrm{H}$, H offmeister $\mathrm{H}$ : B evölkerungsbezogene Krebsregister in der Bundesrepublik D eutschland. R KI Schriften. M ünchen, M edizin Verlag, 1995, vol 3.

$2 \mathrm{H}$ artenstein R: Palliativmedizin aus der Sicht des Internisten; in K laschik E, Nauck F (H rsg): Palliativmedizin - Bestandteil interdisziplinären $\mathrm{H}$ andelns, Frankfurt/M ., pmi Verlagsgruppe, 1996, pp 17-20.

3 Statistisches Bundesamt, Wiesbaden, 1999.

$4 \mathrm{M}$ acD onald $\mathrm{N}$ : The interface between oncology and palliative medicine; in D oyle $D, H$ anks $G, M$ acD onald $N$ (eds): Oxford Textbook of Palliative M edicine, 2nd ed. Oxford, O xford U niversity Press, 1998, p 11.
5 Saunders C: Foreword; in Doyle D, Hanks G $M$ acD onald $N$ (eds): Oxford Textbook of Palliative Medicine, 2nd ed. Oxford, Oxford U niversity Press, 1998, p VII.

6 Jackson A , E ve A : D irectory 2000, The H ospice Information Service at St. Christopher's, L ondon, 2000. 7 Sabatowski R, R adbruch L, L oick G, N auck F, M üller $M$ : Palliativmedizin 2000 - Stationäre und ambulante Palliativ- und $\mathrm{H}$ ospizeinrichtungen in Deutschland. Bonn, Deutsche Gesellschaft für Palliativmedizin, 1999.

$8 \mathrm{C}$ ancer pain relief and palliative care. Report of a WHO Expert Committee. Geneva, World Health Organization, 1990
9 B ruera $E$ : R esearch in symptoms other than pain; in Doyle D, Hanks G, M acD onald N (eds): Oxford Textbook of Palliative Medicine, 2nd ed. Oxford, O xford U niversity Press, 1998, p 179.

$10 \mathrm{~N}$ ational Council for $\mathrm{H}$ ospice and Specialist Palliative Care Services: Specialist Palliative Care: A Statement of Definitions, Occasional Paper 8, O ctober 1995, p 5.

11 E uropean Society for Medical Oncology: The New ESM O Task Force on the Integration of Palliative Care into M edical O ncology. N ewsletter no. 3/1999.

12 Doyle D: Perspectives of Palliative Medicine, Cancer Treat R ev 1996;22(suppl A ):155-161. 